\title{
Linguistic features to compile a successful scientific discourse: Have Tunisian novice researchers ever seen such features during their educational career
}

\author{
Chokri Smaoui $^{1}$, Elhoucine Essefi ${ }^{2}$ \\ ${ }^{1}$ RU: Discourse Analysis, Faculty of Letters and Humanities of Sfax, Sfax, Tunisia \\ ${ }^{2}$ National Engineering School of Sfax, Road of Soukra, km 4 Zipcode3038, Sfax, Tunisia
}

Email address:

hocinsefi@yahoo.fr (E. Essefi)

\section{To cite this article:}

Chokri Smaoui, Elhoucine Essefi. Linguistic Features to Compile a Successful Scientific Discourse: Have Tunisian Novice Researchers Ever Seen Such Features during their Educational Career. International Journal of Language and Linguistics. Vol. 3, No. 1, 2015, pp. 8-15.

doi: $10.11648 /$ j.ij11.20150301.12

\begin{abstract}
This work predicted the difficulties of Tunisian novice researchers with scientific writing by studying, in terms of Functional Linguistics, two linguistic features used in the scientific discourse: syntactic structures and hedging. This work shows the deficiency of the official programs in terms of the required skills to compile a successful scientific discourse. Results showed that Tunisian novice researchers have never seen such features during their acquisition of English. Thus, they may face the hard challenge of packaging the high content of information in such an expository discourse to reach the informative and rhetorical purpose of their scientific products.
\end{abstract}

Keywords: Syntactic Structures, Hedging, Functional Linguistics, Information Packaging, Expository Discourse, Informative Purpose, Rhetorical Purpose

\section{Introduction}

After reviewing the literature, compiling the corpus of a scientific discourse represents the second linguistic stage of producing and selling the scientific product. Being aware of the relation of power with their gatekeepers or examiners, scientific researchers need to master some linguistic features to persuade their target audience of their scientific claims. This work aims to predict difficulties of Tunisian novice researchers with scientific writing by studying two common linguistic features used in the scientific discourse: syntactic structures and hedging. Results show that Tunisian novice researchers have never seen such linguistic features during their acquisition of English. Thus, they may face the hard challenge of packaging the high content of information in such an expository discourse to reach the informative and rhetorical purpose of their scientific products.

\section{Method}

This paper adopts the approach of the Contrastive
Linguistics school (Stockwell and Martin, 1965); it simulates the line of thinking of the strong version of the Contrastive Analysis Hypothesis (CAH). The common point between this paper and the strong version of the $\mathrm{CAH}$ is essentially in using a predictive approach. Analogically to the $\mathrm{CAH}$, this work predicts the difficulties of Tunisian novice researchers with scientific writing by comparing the linguistic requirements to compile a successful scientific discourse with the acquisition of English of these researchers during their educational career, i.e. a comparison between the required and acquired skills. Added to a reference sentence from this work, which will be manipulated according the exemplified features. Following the school of Corpus Linguistics (e.g., Conrad, 2002), linguistic features will be also exemplified from two Tunisian scientific products recently published: a Research Article (Gallela et al., 2009) (4,175 words) and a Master Thesis (Essefi, 2009) $(28,500$ words). 


\section{Gap between the Required Linguistic Features for a Successful Scientific Discourse and the Tunisian Context}

The two scientific products will be interpreted in the framework of two different schools. First, the school of Functional Linguistics (e.g., Finegan, 1999), which is interested in how syntactic structures serve discourse purposes. Second, the school of Rhetoricians (e.g., Bazerman, 2001), which incorporates the social contextualisation in the scientific discourse.

\subsection{Syntactic Structures Used in the Scientific Discourse}

The mastery of the scientific information flow requires a syntactic organisation that is adapted to the scientific discourse, the persuasive communicative context and audience with authority. That is to say, the information packaging arrangements and subsequent choice of syntactic structures adopted were found to be motivated to a great extent by the particularities of scientific discourse context (Gray, 2013; Lim, 2011). Traditionally, information structure is regarded as encompassing the notions of Theme/Rheme and Given/New (e.g., this chapter (Theme/Given) aims to predict difficulties (Rheme/New)) (Halliday et al., 2013). This type of organisation with Given information first and New information second, reinforced by the principle of endweight and final focal stress, is considered to be the unmarked option for organising the information, and is often rendered in English by an SVO structure (e.g., this chapter $(S)$ aims (V) to predict difficulties $(O)$ ), where the grammatical subject of an active verb affords the thematic anchorage, with the verb complex and object constituting the New or Rhematic part of the clause (Halliday et al., 2013). But this SVO order is not always sufficient or suitable to create a coherent scientific text (Rowley-Jolivet and CarterThomas, 2005). In order to respect unmarked information, structure enunciators may be obliged to use a different syntactic arrangement. They may also choose to reverse the usual information packaging arrangements, deliberately placing New before Given, in order to give certain elements of information particular salience or focus (e.g., predicting difficulties (New) is the aim of this chapter (Given)). For these reasons, scientific researchers need to have at their disposal a battery of linguistic resources so as to indicate unambiguously the most appropriate information packaging arrangement. Specialised syntactic structures such as the passive, cleft constructions, extraposition, inversion and existential 'there', which enable the author to manipulate different clause constituents and thus explicitly denote a particular information packaging arrangement, are theoretically available at all times. Nevertheless, their deployment requires a certain pragmatic competence. All of these pragmatically motivated features, as we shall see in the detailed discussion of each specialised structure, play a decisive role in creating a scientific discourse that is contextually appropriate and rhetorically effective.
Obviously, it will be also proved that Tunisian novice researchers have never seen some of these linguistic features and have never explicitly discussed the utility of others.

\subsubsection{Passive}

Traditionally, the passive has been considered as one of the principal means of achieving impersonality in the scientific text, as it enables the removal of any explicit agency (e.g., difficulties are predicted). An equally important function of the passive however lies in its information structure role. Using a passive structure enables the writer to manipulate clausal constituents and to place (a) specific item(s) in theme position (e.g., difficulties), especially when there is a choice of candidates for topichood (Quirk et al. 1985). The author can thematise and present as Given what would normally have been a syntactic object, and hence part of the Rheme, in an active clause, thus respecting the usual unmarked information packaging arrangements. This syntactic structure is used in Research Theses (RT) and Research Articles (RA). This structure is used 174 times in Essefi (2009); e.g., (1) "Second, a hypothetical meteorological station was created within Sidi El Hani discharge playa, in which meteorological parameters were calculated in order to study the response of the potential evaporation to the physical climatic forcing. It was quite evident that the potential evaporation responses linearly to the physical forcing imposed by the climate" (Essefi, 2009). This structure is used 18 times in Gallela et al. (2009); e.g., (2) "Mineralogical analysis was done using the polarizing microscope" (Gallela et al., 2009).

As for Tunisian novice researchers, eventhough this syntactic structure is taught starting from the secondary level, its importance in the compilation of scientific discourse bas never been explicitly discussed in the official Tunisian programs. Thus, it is good-for-nothing; since Tunisian novice researchers are not aware of its utility.

\subsubsection{Extraposition}

The high frequency of extraposition may be due to its role in information packaging. In extraposition, the semantically empty or anticipatory 'it' in initial position in the matrix clause refers to a clausal item, non-finite or finite, placed in the postponed extraposed clause (e.g., it is the aim to predict difficulties) (Quirk et al. 1985). Thanks to extraposition, not only heavy or complex grammatical units are placed towards the end of the sentence (e.g., to predict difficulties), thus easing processing for the receiver and respecting the endweight principle, but also any new elements of information will automatically occur in the Rheme position, ensuring an increase in communicative dynamism along the left to right axis of the clause. Another explanation for the high frequency of extraposition in the scientific discourse is related to the hedging concerns phenomenon (e.g., it is possible to predict difficulties in this chapter). The scientist can thus make a subtle commentary on the validity of the information placed in the extraposed clause without appearing overtly in the text. Moreover, by placing this comment in clause-initial position, the position where 
readers expect Given (not New) information to occur, the evaluation becomes particularly difficult to challenge and is therefore rhetorically more effective (e.g., Hewings and Hewings, 2002). Example (3) illustrates also the link between this structure and the passive. Nearly half of the cases of extraposition in the NS articles use a passive (Rowley-Jolivet and Carter-Thomas, 2005). The combination of these two structures reinforces this impression of objectivity. Extraposition is a frequent structure in Research Theses (RT) and Research Article (RA), where it regularly occurs as semi formulaic lexical bundles such as in (3) "it is worth noting that" (Essefi, 2009; 15 times) and in (4) "It is reasonable to assume that desilicification took place mainly by a destruction of alumino-silicates during weathering" (Gallela et al., 2009). When comparing how the NS and NNS use extraposition in their articles, Rowley-Jolivet and CarterThomas (2005) have noticed that NS use it heavily $(3.6 \%$ of clausal choices), whereas NNS use it less frequently $(2.4 \%$ of clausal choices) (Fig. 1), indicating perhaps that NNS scientists are not using extraposition to its full advantage and may be in fact not fully aware of its informational and evaluative potential.

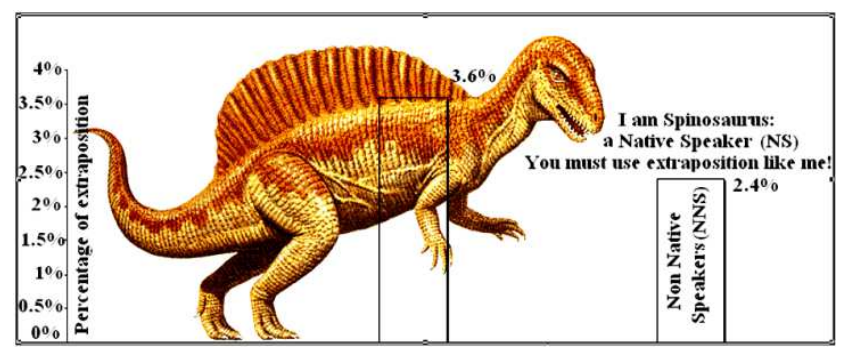

Fig 1. Percentages of extraposition of Native Speakers (NS) and Non Native Speakers (NNS): in face of the dinosaurian behaviour of (NS), (NNS) like Tunisian novice researchers must follow (NS) standards.

As for Tunisian novice researchers, it seems that this syntactic structure has never been introduced to them during their acquisition of English. This item is taught only to students of second year general English. Thus, it may be concluded that Tunisian official programs contain a lacuna forbidding the compilation of a successful scientific discourse.

\subsubsection{Inversion}

Inversion is another syntactic structure that can be used to manipulate the positioning of elements in the clause, thus creating a different information packaging arrangement. The reversal of the canonical or unmarked English SV (O) sequence can be achieved in two ways. First, Subject/Operator (or partial) inversion is not frequent in use (Quirk et al. 1985). For instance, Essefi (2009) used it once; (5) "Nevertheless, it will not predict discharge playa or groundwater environment global changes, nor will it predict how changes in climate will affect its entire hydrological cycle". Second, Subject/Verb (or full) inversion is also rare in use. Neither Essefi (2009) nor Gallela et al., (2009) used such a structure.

As for Tunisian novice researchers, they are not familiar with such a structure. As an illustration of this, example (5) was discussed with ten Tunisian novice researchers. Many of them are surprised by using the expression (nor will it); they believe that the author would have been mistaken by using it instead of (nor it will).

\subsection{4. $\mathrm{WH}$-Clefts}

Ordinary WH-clefts (WH) have the following form: WH$\mathrm{P}_{-}$is $\mathrm{X}$; (e.g. what this chapter aims to do is to predict difficulties). Generally, it is used in Theses and articles; e.g., (6) "Sure enough results will be a matter of debate. But what is for sure is that the idea and the demarche are quite defendable" (Essefi, 2009). WH-clefts do not change the canonical information structure pattern Theme/Rheme. The initial relative clause is presented as background information and the cleft item is presented as New in the usual rhematic position. However, thanks to the cleft construction the division between Given and New is highlighted, and as a result the listener is encouraged to pay attention to the New elements, which receive additional focus (Quirk et al. 1985). The WH-cleft could also be considered as an interactive strategy, implying some sort of questioning process (Thompson, 1996). As in the above example (6), WH-clefts would be seen as an underlying presupposed question that either the audience is likely to ask at that stage, or that the researchers asked themselves at that point. Example (6) is then an implicit answer to a virtual question [are results of this demarche relevant?].

As for Tunisian novice researchers, it seems that this syntactic structure has never been discussed during their acquisition of English.

\subsection{5. $\mathrm{RWH}$-Clefts}

In Reversed WH-clefts (RWH), the clefted constituent occurs in sentence initial position: X is WH-P0 (Quirk et al. 1985) (e.g., this chapter aims to predict how difficulties are). This syntactic structures is used in Thesis; e.g., (7) "The Schepard's classification, Folk classification and verbal description are to show, at the very same, how important the combination of two classification schemes such as of Shepard (1954) and Folk (1974) is and how debatable the results of the descriptive grain size distribution are (Essefi, 2009). Unlike the regular WH-cleft, where the canonical information packaging arrangements are respected, in RWHclefts the highlighted focal information occurs in thematic position and the backgrounded relative clause appears rhematically.

\subsection{Hedging in the Scientific Discourse: Epistemological and Social Requirements}

Hedging is motivated by both epistemological and social factors. On the one hand, there is epistemologically the uncertainty of science since certainty is impossible for scientific enquiry. Science deals with probabilities and theories (e.g., this chapter predicts potential difficulties). In the context of this uncertainty, hedges have been seen as linguistic features that help writers to present statements with 
appropriate accuracy and caution, and as resources that help scientists express the correct degree of their certainty to their claims (e.g., Hyland, 1996) (e.g., this chapter may predict difficulties). On the other hand, there are, socially, power asymmetries between contributors and disciplinary gatekeepers or examiners, which dictate that contributors allow room for alternative interpretations, and tone down their claims in order to solicit acceptance for them (e.g., Hyland, 1996). Hyland (1996, 1998, 2000) proposed two categories of hedging techniques: lexical and discoursebased or strategic (see below). Recently, Koutsantoni (2006) discussed in detail the taxonomy of hedging. Hedging techniques can be traced back to awareness of power asymmetries in disciplinary communities. Being aware of examiners' or gatekeepers' statuses, the author of (RT) or (RA) use these linguistic features to persuade the scientific community of his claims.

\subsubsection{Lexical Hedging}

According to the literature, there are six main categories in the taxonomy of lexical hedges (Hyland, 1996, 1998); the following part will examine these features and will give statistics about their use in Essefi (2009) and Gallela et al. (2009). This statistical study will count the occurrence of some items; then, it will calculate their densities by dividing them by the total number of words in the document (it is different from the statistical study of Rowley-Jolivet and Carter-Thomas (2005)). (Density of item $=$ (occurrence of item /total number of words) x100).

\subsubsection{Modal Verbs}

To tone down their discourse, authors use modal verbs expressing possibility and probability such as the modal verb 'may' to express their modesty in declaring their claims (e.g.,
(8). "A cross interpretation of these mentioned events may explain the present filling of Sidi El Hani saline environment" (Essefi, 2009)); e.g., (9) "This may indicate that the basin was closer to the provenance area" (Gallela et al., 2009). 'Can' as a modal verb also expresses possibility in such contexts; e.g., (10) "because the contamination by the migrated hydrocarbon can falsify results" (Essefi, 2009); e.g., (11) "The granulometric distribution of the samples can be related to mineralogical composition" (Gallela et al., 2009). The degree of hedging increases with the use of the past of the model verb like 'might' (Quirk et al. 1985) ; in a past context, the modal is followed by the auxiliary 'have' and the past participle; e.g., (12) "The huge quantities of salt in Sidi El Hani playa might have been, then, the result of a leaching of Triassic domes" (Essefi, 2009); e.g., (13) "Their source areas might have been subjected to a low degree of weathering" (Gallela et al., 2009). The use of the modal verb 'could' is equally meant to express less possible events, and in a past context, the same requirements for 'might' are needed; e.g., (14) "This could characterize periods with high frequency of intense precipitation events, most probably during the warm season" (Essefi, 2009); e.g., (15) "The Barremian sediments could thus possibly have been derived from erosion of uplifted mainly sedimentary rocks" (Gallela et al., 2009). By examining the occurrence and density of some modal verbs in (Essefi, 2009) and (Gallela et al., 2009) (Tab: 1), it may be noticed that Theses contain more of this syntactic structure due to the awareness of their awareness about the relation of power with their examiners. Thus, Tunisian novice researchers have not developed this linguistic device due to a problem of genre awareness and a deficiency in the official programs.

Tab 1. Occurrence and density of some modal verbs in (Essefi, 2009) and (Gallela et al., 2009).

\begin{tabular}{lllll}
\hline & $\begin{array}{l}\text { Number of item in (Essefi, } \\
\text { 2009) }\end{array}$ & $\begin{array}{l}\text { Density of item ((i/w) \%) } \\
\text { in (Essefi, 2009) }\end{array}$ & $\begin{array}{l}\text { Number of items in } \\
\text { (Gallela et al., 2009) }\end{array}$ & $\begin{array}{l}\text { Density of items ((i/w) \%) } \\
\text { in (Gallela et al., 2009) }\end{array}$ \\
\hline May & 95 & $0.33 \%$ & 8 & $0.19 \%$ \\
Can & 46 & $0.16 \%$ & 2 & $0.04 \%$ \\
Might & 9 & $0.03 \%$ & 1 & $0.02 \%$ \\
Could & 34 & $0.12 \%$ & 5 & 0.12 \\
Modal verbs & 197 & $0.7 \%$ & 26 & $0.62 \%$ \\
\hline
\end{tabular}

\subsubsection{Epistemic Lexical Verbs}

Epistemic lexical verbs (suggest, believe, appear, seem, propose, attempt) (Tab: 2) are categorised into judgmental verbs and evidential verbs. On the one hand, the judgmental category is further subdivided into speculative and deductive (cognitive) verbs (Hyland, 1996, 1998). First, the speculative verbs category includes verbs that are performative such as 'propose' and 'suggest'; e.g., (16) “This study proposes its own scenario for an inherited Sidi El Hani playa from the Messinian Time" (Essefi, 2009); e.g., (17) "Pettijohn et al. (1973) proposed a classification of terrigenous sandstones on the basis of $\log (\mathrm{Na2O} / \mathrm{K} 2 \mathrm{O})$ versus $\log (\mathrm{SiO} 2 / \mathrm{Al} 2 \mathrm{O} 3)$ " (Gallela et al., 2009); e.g., (18) "As for the quantitative identification, many authors (e.g., Khalil et al., 2006) suggest that the models of salt and water budget are commanded by a differential equation because they believe that a deterministic chaotic system behaves in the future in a similar manner as in the past" (Essefi, 2009); e.g., (18) "A Barremian age has been suggested (Ben Ferjani et al., 1990; Chekhma, 1996; Azaïez et al., 2007)" (Gallela et al., 2009). Second, cognitive verbs such as 'believe' or 'speculate' are also used in scientific texts. On the other hand, evidential verbs are subdivided into sensory verbs, and verbs indicating the way of acquisition of evidence. sensory verbs such as 'appear' and 'seem' are used in RA and RT; e.g., (19) 'In such a diagram, similarity between samples generally appears in spite of the different concentrations" (Essefi, 2009); e.g., (20) "Most angular grains appear to be broken and have uneven surfaces" (Gallela et al., 2009); e.g., (21) 
"this correlation seems less evident because the distinction between sediments within even the same core is quite difficult" (Essefi, 2009); e.g., (22) "The $\mathrm{SiO}_{2}$ content in all the studied sections seems to decrease with increasing $\mathrm{Al}_{2} \mathrm{O}_{3}$ " (Gallela et al., 2009). Verbs that indicate the means by which evidence was acquired, such as 'seek' and 'attempt' (Hyland, 1996, 1998) are also found in the studied samples; e.g., (23)
"Nevertheless, this study attempt on the basis of the available data and materials to guess, with the grey scale variability and the grain size distribution, the climatic variability" (Essefi, 2009); e.g., (24) "The main aims of this study are to investigate the sedimentary features and attempt to determine the paleoenvironment, provenance and tectonic setting, of the Sidi Aïch Formation" (Gallela et al., 2009).

Tab 2. Occurrence and density of some Epistemic lexical verbs in (Essefi, 2009) and (Gallela et al., 2009).

\begin{tabular}{|c|c|c|c|c|}
\hline & $\begin{array}{l}\text { Number of item in (Essefi, } \\
\text { 2009) }\end{array}$ & $\begin{array}{l}\text { Density of item }((\mathbf{i} / \mathbf{w}) \%) \\
\text { in (Essefi, 2009) }\end{array}$ & $\begin{array}{l}\text { Number of item in } \\
\text { (Gallela et al., 2009) }\end{array}$ & $\begin{array}{l}\text { Density of item ((i/w) \%) } \\
\text { in (Gallela et al., 2009) }\end{array}$ \\
\hline Suggest & 15 & $0.05 \%$ & 12 & $0.28 \%$ \\
\hline Propose & 14 & $0.05 \%$ & 1 & $0.02 \%$ \\
\hline Appear & 17 & $0.06 \%$ & 1 & $0.02 \%$ \\
\hline Seem & 24 & $0.08 \%$ & 1 & $0.02 \%$ \\
\hline Epistemic lexical verbs & 70 & $0.24 \%$ & 15 & $0.35 \%$ \\
\hline
\end{tabular}

\subsubsection{Epistemic Adverbs and Adjectives}

Epistemic adverbs and adverbials (somewhat, usually, possibly, probably), epistemic adjectives (possible, likely) (Tab: 3) are common items in scientific texts. They may be used to express prudence about a previous result; e.g., (25) "The Sidi Aïch Formation, which is probably Bargeman in age, was deposited in central and southwestern Tunisia" (Gallela et al., 2009) and they may also be used to show the possibility of obtaining results in the future e.g., (26) "In this context, it may be suggested that Sidi El Hani saline environment is probably a good terrestrial analogous to study the sedimentation on Mars" (Essefi, 2009). They may also be used to make the choice between two possibility; e.g., (27) "The Beta Island may be formed by a wind deflation or a tectonic uplift; seeing the geological context of Sidi El Hani clay pan, both hypotheses are possible" (Essefi, 2009); e.g., (28) "Such studies are essential to understand paleoenvironments of deposition inferred for these rocks, and to identify possible origins of the sediment" (Gallela et al., 2009). They may be used to express approximation, namely with values of experiences and measurements e.g., (29) "Fresh igneous rocks and feldspar have average CIA values approximately of 50" (Gallela et al., 2009); e.g., (30) "The Sidi El Hani playa surface is approximately 35000ha" (Essefi, 2009). They are used in the results section to interpret results; e.g., (31) "Thus, the dissolution of halite is more likely to occur with a coming up of salty water to Sidi El Hani discharge playa" (Essefi, 2009); e.g., (32) "These sediments most likely accumulated in environments where current action was either weak or deposition was very rapid*" (Gallela et al., 2009).

Tab 3. Occurrence and density of some Epistemic adverbs and adjectives in (Essefi, 2009) and (Gallela et al., 2009).

\begin{tabular}{lllll}
\hline & $\begin{array}{l}\text { Number of item in } \\
\text { (Essefi, 2009) }\end{array}$ & $\begin{array}{l}\text { Density of items ((i/w) \%) in } \\
\text { (Essefi, 2009) }\end{array}$ & $\begin{array}{l}\text { Number of items in } \\
\text { (Gallela et al., 2009) }\end{array}$ & $\begin{array}{l}\text { Density of items ((i/w) \%) } \\
\text { in (Gallela et al., 2009) }\end{array}$ \\
\hline Probably & 14 & $0.05 \%$ & 6 & $0.14 \%$ \\
possible & 4 & $0.01 \%$ & 1 & $0.02 \%$ \\
approximately & 14 & $0.05 \%$ & 1 & $0.02 \%$ \\
likely & 21 & $0.07 \%$ & 1 & $0.02 \%$ \\
Epistemic adverbs and adjectives & 53 & $0.18 \%$ & 9 & $0.21 \%$ \\
\hline
\end{tabular}

\subsubsection{Epistemic Nouns}

Epistemic nouns (probability, possibility...) (Tab: 4) increase objectivity and modesty of claims and afford more protection from critics. Examiners and gatekeepers are more than likely to tolerate the lack of results e.g., (33) "In spite of the difficulty to separate the fine fraction and the failure of classification methods to differentiate bands, the grain size distribution has given some results" (Essefi, 2009) and some over-interpretation of the author; e.g., (34). "First, the gravimetric data suggest the possibility of a hydrocarbon reservoir located in evaporitic domes in the vicinity of Sidi El Hani playa” (Essefi, 2009).

Tab 4. Occurrence and density of some Epistemic adverbs and adjectives in (Essefi, 2009) and (Gallela et al., 2009).

\begin{tabular}{lllll}
\hline & $\begin{array}{l}\text { Number of items in } \\
\text { (Essefi, 2009) }\end{array}$ & $\begin{array}{l}\text { Density of items ((i/w) \%) } \\
\text { in (Essefi, 2009) }\end{array}$ & $\begin{array}{l}\text { Number of items in } \\
\text { (Gallela et al., 2009) }\end{array}$ & $\begin{array}{l}\text { Density of items ((i/w) \%) in } \\
\text { (Gallela et al., 2009) }\end{array}$ \\
\hline Probability & 0 & $0 . \%$ & 0 & $0 \%$ \\
Possibility & 19 & $0.06 \%$ & 0 & $0 \%$ \\
Complexity & 0 & $0 \%$ & 0 & $0 \%$ \\
Difficulty & 5 & $0.02 \%$ & 0 & $0 \%$ \\
Epistemic adverbs and adjectives & 24 & $0.08 \%$ & 0 & $0 \%$ \\
\hline
\end{tabular}




\subsubsection{Indefinite Articles and Numerals with Countable Nouns}

Indefinite articles associated with countable nouns (e.g., a way to) are meant to generalize the interpretation by focusing on indefiniteness of cases that support the interpretation; e.g., (35) "From $140 \mathrm{~cm}$ to $172 \mathrm{~cm}$ the high major grey scale is a sign of a stable climatic condition" (Essefi, 2009). Numerals with countable nouns (e.g., one way to) are useful to precise the definiteness of possibility; e.g., (36) "In order to solve the problem of having fine grain size, this method followed two lines of attack: Inclusive Graphic Statistics (IG) and Moments Statistics (MM)" (Essefi, 2009).

\subsubsection{General Determiners with Countable Nouns}

General determiners with countable nouns give anaphoric reference to previously mentioned items; hence, the reader must establish a logical link between what will be discussed and previous comments (Cowen 2008); these features also increase the cohesion of text and enhance coherence in the mind of readers (e.g., another aim of this chapter is to predict difficulties); e.g., (37) "Another possibility of origin of salt and/or salty water is added to the possibility of the Triassic intrusions in the subsurface of the Sahel area" (Essefi, 2009).

\subsubsection{Strategic Hedges}

Strategic hedging includes whole sentences that refer to limitations of the study, the methodology or model used, and admission of lack of knowledge. Since they are normally identified only in context, their counting is difficult. Authors try to point out these limitations before their audience. In both (RA) and (RT), strategic hedges fall into five categories (Koutsantoni, 2006): limitations of method, limitations of the scope of the paper, limited knowledge, agreement with other research, and limitations of the study (reference to testability).

\subsubsection{Limitations of Method/Technique/Tool/Algorithm}

This type of strategic hedging acknowledges limitations of the method used in experiments or simulations, tools, techniques or algorithms, which are part and parcel of experimental work. Such strategic hedges are employed by authors to protect themselves from negative criticism and to admit the limitations before they are pointed out by journal referees and peer reviewers or examiners. For instance, in Essefi (2009), the author anticipated that he would be harshly criticized for not giving a clear literature review about Sidi El Hani; accordingly he filled the gap by giving reasons; e.g., (38) "the overlap between local (e.g. Tyrrhenian) and standard (e.g. Messinian) terminologies makes collecting a clear literature review next to impossible" (Essefi, 2009). Anticipating criticism about the use of the grey scale, the author also gives reference to some technical problems; e.g., (39) "To detect even the major grey scale variability in this core, image software is needed; hence, it is impossible to correlate it with other cores on the basis of this demarche" (Essefi, 2009). Being aware of the limitations of his results, the author auto-criticized his work; e.g., (40) "As it is quite evident, the descriptive grain size distribution is still far from being efficient to give an idea about the hydrodynamics. This approach stands in the descriptive area" (Essefi, 2009). However, in some cases, even though authors do acknowledge such limitations, they go on to stress the advantages of their method, tools, techniques, etc., and to point out that these limitations do not significantly affect their results; e.g., (41) "This approach stands in the descriptive area. Nevertheless, one can say that the clayey fraction is associated with a calm depositional environment and the sandy fraction is associated with more agitated depositional environment (Essefi, 2009). Theses authors attempt to counterbalance the limitations mostly by attempting to justify their methodological choices, and by indicating that there were problems even though the necessary precautions were taken; e.g., (42) "Added to the AFNOR series, the sieves $50 \mu \mathrm{m}$ and $40 \mu \mathrm{m}$ are added to overcome the technical difficulty of having fine grain size. But it is revealed that much is still to be done to recuperate the entire fine fraction" (Essefi, 2009).

Acknowledgments of limitations in Theses might thus be characterised as more honest, as when starting a research project, students do not know in advance the problems they might face, and the Thesis needs to be completed within certain time limits and often with limited resources. This means that after the required time has elapsed, students have to write up that research irrespective of whether or not they have obtained significant results. The only solution is to acknowledge the problems and limitations, and counterbalance the hedge by attempting to justify their choices and indicate that they did take some precautions. On the other hand, RA authors are free to choose which account to send for publication; that is to say, they are not expected to send accounts of work that were problematic and did not produce significant results. As Knorr-Cetina (1981) observed, certain aspects of laboratory work, such as results being the result of specific methodological decisions and methods chosen with a view to anticipated results, are often concealed from public scrutiny in the Research Article.

\subsubsection{Limitations of the Scope of the Paper/Thesis}

This type of strategic hedging acknowledges the limitations of the scope of the paper. By using such a feature, the authors pinpoint what they have chosen to discuss in it and what is outside their line of study. For example, in Essefi (2009), the author anticipates that the readers will look for quantification; accordingly he warns them that it is not his line of study; e.g. (43) "Nevertheless, it will not predict discharge playa or groundwater environment global changes, nor will it predict how changes in climate will affect its entire hydrological cycle" (Essefi, 2009). The author also warns his readers that even though he finds out the equation he will not go far with it; e.g., (44) "This equation will not be 
computed" (Essefi, 2009). In Theses, these limitations seem to be mainly motivated by failed experiments and circumstances outside of the students' control. As the example below indicates, the decision of what to include in the Thesis is not a conscious one taken before the writing of the Thesis.

\subsubsection{Limitations of Knowledge}

These hedges acknowledge the inability to always offer explanations for phenomena, limitations of the scope of definitions and suggested models. For example, in the Thesis of Essefi (2009), the author feels that he did not give a satisfactory interpretation of some results. Consequently, he blames it on the problem of dating; e.g., (45) "The description of remaining parts of cores, in which no attempts of dating were done, tries not to fall into over- or misinterpretations; because $1 \mathrm{~m}$ of sediments may depose in one day as it may depose in thousands of years. Thus, it is better to be satisfied only with descriptive results" (Essefi, 2009). Even though RA authors admit limited knowledge more than do students, their strategic hedging still connotes power and authority on their part to make the claim (Hyland, 2001). On the other hand, students cannot claim to be in that position and to definitely say that knowledge in a certain area is lacking as they may not be familiar with all of the research in an area and may feel that admitting lack of knowledge might weaken their theses.

\subsubsection{Agreement with other Research}

Agreement with other research constitutes a strategic hedging as authors express tentativeness regarding their findings by seeking support from external sources, suggesting that they are not alone in their suggestions and that there are other researchers with similar suggestions and results. As Hunston (2000) maintains, when statements are attributed to other research, the responsibility is generally shifted. For instance, in Essefi (2009), the author is aware that, when discussing the Messinian in his Master, he will be criticized in terms of geological Time; hence, he tries to protect himself by referencing the problem of time from the literature; e.g., (46) "Paleomagnetic and astrochronologic studies indicate that the Messinian Salinity Crisis developed between circa 5.94-5.96 and 5.32 Ma (e.g. Krijgsman et al., 1999)" (Essefi, 2009). At the same time, authors demonstrate familiarity with the research conducted in their field and 'strengthen their claims through the replicability of experimental procedures' (Hyland, 2002). In Gallela et al. (2009), the authors try to show off their mastery of the Tunisian landscape by referencing some old and recent previous studies; e.g., (47) "Previous stratigraphical and sedimentological studies carried out on the Early Cretaceous outcrops (Burollet, 1956; M'Rabet, 1987; Ben Ferjani et al., 1990; Chekhma et al., 1990; Chaabani et al., 1992; Ben Youssef, 1999; Chaabani and Razgallah, 2006) showed that the sedimentary rocks are organized in major sequences and that central Tunisia was dominated by shallow marine sedimentation in a mosaic of intra-shelf basins" (Gallela et al., 2009).

\subsubsection{Limitations of the Study}

These hedges refer to the testability of the study and acknowledge the need for further research in order to validate the findings of the study. In this way, authors indirectly indicate that their results are not definitive and that there is a scope for further work. For instance, in the Thesis of Essefi (2009), the author opens up new perspectives by pinpointing the debate about doing the grain size distribution; e.g., (48) "Actually, an as yet open debate is still between geologists whether to use descriptive or genetic classification" (Essefi, 2009). The difference in frequency of use of this type of strategic hedge in the RAs and Theses could be explained with regard to authors' status in the academic community, the authoritativeness they can assume, and the confidence they can show in the significance of their study. RA authors can claim a higher level of expertise and authoritativeness possibly supported with previous acceptance of their claims by the community in RAs or Theses. On the other hand, student researchers can be assumed to feel insecure about the validity of their claims as they are pending acceptance by their examiners.

\section{Conclusion}

By enumerating the linguistic features required to compile a successful academic discourse and examining the history of language acquisition of Tunisian researchers, one can predict that Tunisian novice researchers are more than likely to face rejection from the international scientific community. In fact, the official programs lack many of the linguistic features used in the scientific discourse. The lack of these skills is also linked to the awareness of the relation of power within the scientific discourse, because the pragmatic use of these linguistic features necessitates a good understanding of the game of power in the scientific discourse.

\section{Corpus}

Essefi, E. (2009). Multidisciplinary study of Sidi El Hani Saline Environment: the History and the Climatic Variability. Master thesis, Faculty of sciences of Sfax (2009).

Gallala, W., Gaied, M.E., Essefi, E., Montacer, M., 2010. Pleistocene calcretes from eastern Tunisia: The stratigraphy, the microstructure and the environmental significance. Journal of African Earth Sciences 58, 445-456.

\section{References}

[1] Bazerman, C. (2001). Nuclear information: one rhetorical moment in the construction of the information age. Written Communication, 18,259-295.

[2] Conrad, S. (2002). Corpus linguistic approaches for discourse analysis. Discourse and dialogue, 22, 75-94, New York Cambridge University Press.

[3] Cowen, R. (2008). The Teacher's Grammar of English: A Course Book and Reference Guide. Cambridge University Press. 
[4] Gray, B. (2013). More than discipline: uncovering multidimensional patterns of variation in academic research articles. Corpora, 8(2), 153-181.

[5] Finegan, E. (1999). Language: Its structure and use (3 $3^{\text {rd }}$ ed.). New York: Harcourt.

[6] Hyland, K. (1998). Hedging in scientific research articles. Amsterdam: John Benjamins.

[7] Hyland, K. (1999). Disciplinary discourses: Writer stance in research articles. In C. N. Candlin, \& K. Hyland (Eds.), Writing: Texts, processes and practices (pp. 99-121). London: Longman.

[8] Hyland, K. (2000). Disciplinary discourses: Social interactions in academic writing. London: Longman.

[9] Hyland, K. (2001). Bringing in the reader. Written Communication, 18(4), 549-574.

[10] Hyland, K. (2002). Authority and invisibility: Authorial identity in academic writing. Journal of Pragmatics, 34, 1091-1112.

[11] Hyland, K. (1996).Writing without conviction? Hedging in scientific research articles. Applied Linguistics, 17(4), 433453 .
[12] Halliday, M., Kirkwood, M A., Matthiessen, C M., 2013. Halliday's introduction to functional grammar. Routledge.

[13] Hewings, M., \& Hewings, A. (2002). A comparative study of anticipatory_it_in student and published writing. English for Specific Purposes, 21, 367-383.

[14] Koutsantoni, D. (2006). Rhetorical strategies in engineering research articles and research theses: Advanced academic literacy and relation of power, Journal of English for Academic Purposes, 5, 19-36.

[15] Lim, J. M. H. (2011). 'Paving the way for research findings': Writers' rhetorical choices in education and applied linguistics. Discourse Studies, 13(6), 725-749.

[16] Quirk, R., Greenbaum, S. \& Leech, G. (1985). A Comprehensive Grammar of the English Language. Harlow: Longman.

[17] Rowley-Jolivet. E., Carter-Thomas. S. (2005). Genre awareness and rhetorical appropriacy: Manipulation of information structure by NS and NNS scientists in the international conference setting. English for Specific Purposes, $24,41-64$.

[18] Stockwell, R.P., and Martin, J. W. (1965). The grammatical structure of English and Spanish. Chicago: University of Chicago Press. 